\title{
ANÁLISE MORFOESTRUTURAL EM ÁREA DE OCORRÊNCIA DE ARENITO ASFÁLTICO, BACIA DO PARANÁ, SÃO PAULO
}

\author{
Carlos César de ARAÚJO \\ Jorge Kazuo YAMAMOTO \\ Vanessa MADRUCCI
}

\begin{abstract}
RESUMO
Arenitos asfálticos ocorrem na borda leste da Bacia do Paraná, Estado de São Paulo. As ocorrências estão relacionadas a condicionantes estratigráficos, estruturais e geomorfológicos. Desse modo, uma análise morfoestrutural foi feita para estabelecer quais elementos geomorfológicos refletem os controles geológicos relacionados à gênese dos arenitos asfálticos. A análise morfoestrutural foi baseada no mapa da rede de drenagem e em imagens de sensoriamento remoto. A interpretação considerou os lineamentos de relevo e a delineação das principais flexuras do terreno. O método de interpretação foi baseado na identificação de anomalias de drenagem, que correspondem a modificações geométricas em relação ao padrão de drenagem regional, como anomalias anelares, radiais e padrões assimétricos. Além disso, foram interpretadas feições retilíneas de drenagem, de mesmo comprimento; estas feições representariam zonas de juntas. Foram detectadas várias anomalias de drenagem na área de ocorrência de arenito asfáltico, várias delas relacionadas a estruturas geológicas mapeadas. Desse modo, o mapa morfoestrutural com a delineação de altos e baixos e os lineamentos são os principais elementos geomorfológicos que refletem os fatores geológicos relacionados à ocorrência de arenito asfáltico. As ocorrências encontram-se em áreas de alta e média densidade de zonas de juntas. Terrenos fraturados são favoráveis à migração dos hidrocarbonetos mas também, à erosão do depósito, agindo de forma antagônica em tempos diferentes. As principais estruturas geológicas da área, estrutura do Jacu e Alto Estrutural de Anhembi, são exemplos da relação entre substrato geológico e relevo, o que ajuda no entendimento da gênese das ocorrências.
\end{abstract}

Palavras-chave: arenito asfáltico, Bacia do Paraná, morfoestrutura, lineamento, zonas de juntas.

\section{ABSTRACT}

Tar sandstones occur in the Eastern Border of the Paraná Basin, São Paulo State. The occurrences are related to stratigraphical, structural and geomorphological constraints. A morphostructural analysis was performed to establish the relationships between geomorphological features and the geological elements related to tar sandstone genesis. The morphostructural analysis was based on the drainage network map and on remote sensing images. The interpretation has considered the drainage and relief lineaments and the delineation of the main relief flexures. Interpretation is based on the identification of drainage anomalies corresponding to geometric modifications of the regional drainage pattern, such as annular and radial anomalies and asymmetric patterns. Additionally were interpreted linear drainage features with the same length. These features represent joint zones. Many drainage anomalies were detected on the tar sandstone occurrence area, many of them related to geological structures mapped. Thus, the morphostructural map with the delineation of highs and lows and the lineament interpretation are the main geomorphological elements reflecting the geologic factors related to the tar sand occurrence. The occurrences are located in joint zones of high and medium density. Fracture density favors hydrocarbon migration, but also, contradictorily, at different times, erosion of the deposits. The main geological structures in the area, Jacu Structure and Anhembi High, are examples of relationship between geology and relief, helping to explain the genesis of tar sandstones.

Keywords: tar sandstone, Paraná Basin, morphostructure, lineaments, joint zones. 


\section{INTRODUÇÃO}

Na borda leste da Bacia do Paraná, Estado de São Paulo, são encontradas ocorrências de arenitos asfálticos (Figura 1), cuja localização relaciona-se a fatores estruturais e estratigráficos (ARAÚJO 2003). O mapeamento de estruturas geológicas na área de afloramento das ocorrências contribuiu para o entendimento dos processos de migração e acumulação. Estas estruturas têm reflexos na conformação do terreno e, desse modo, a análise morfoestrutural auxilia o entendimento da gênese destas ocorrências.

As principais estruturas regionais, presentes na área, são o Lineamento Tietê, Lineamento Paranapanema, Lineamento Barra Bonita-Itu e a Falha Jacutinga; as falhas Santo Anastácio e Guapiara ocorrem ao sul da área de estudo.

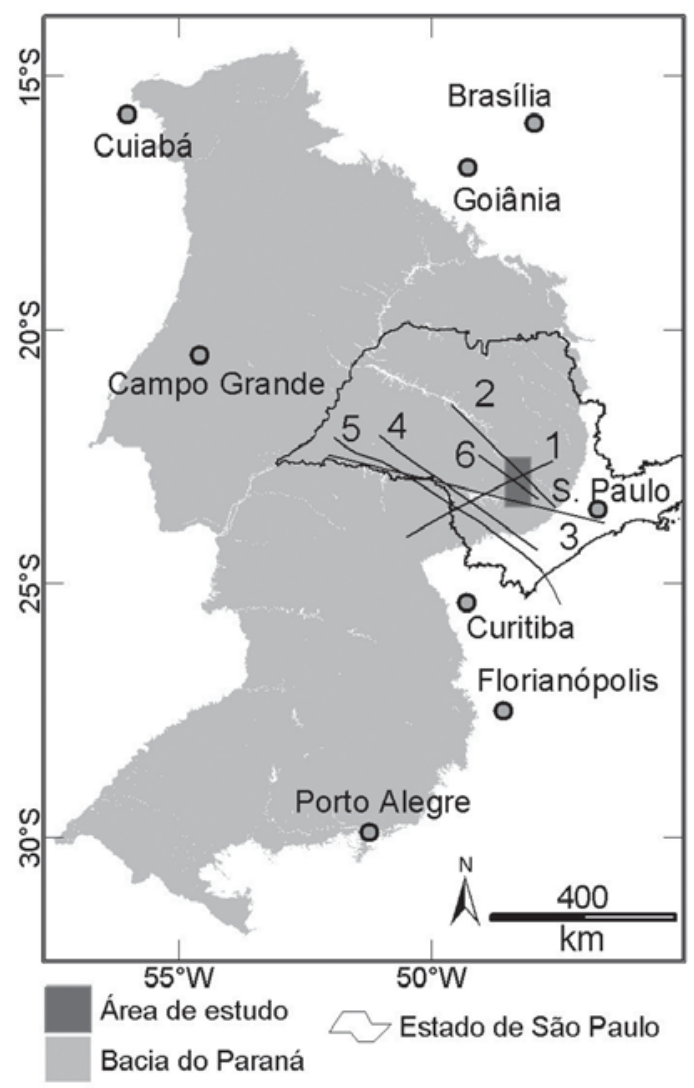

FIGURA 1 - Localização da área de estudo em relação à Bacia do Paraná e Estado de São Paulo e principais estruturas regionais. (1) Falha Jacutinga; (2) Lineamento Tietê; (3) Lineamento Paranapanema; (4) Falha Guapiara; (5) Falha Santo Anastácio; (6) Lineamento Barra Bonita-Itu.
Na área de estudo (Figuras 1 e 2A) afloram rochas do Subgrupo Irati (HACHIRO et al. 1993), das Formações (Fm.) Serra Alta e Teresina (Permiano) e do Grupo São Bento (Triássico-Jurássico). Na base da sequiência aflorante, estão as rochas do Subgrupo Irati compostas por sucessões de folhelhos e calcários. Em seguida, encontram-se os litotipos da Fm. Serra Alta (na base) e Fm. Teresina (no topo), compostos basicamente por siltitos arroxeados intensamente fraturados. No topo da Fm. Teresina encontra-se a Camada Porangaba (MATOS 1995, MATOS \& COIMBRA 1997), composta por brechas, ora de matriz pelítica, ora de matriz arenosa, com intraclastos. Existem aproximadamente 25 ocorrências de arenitos asfálticos na região dos municípios de Anhembi, Bofete, Guareí e Angatuba. As ocorrências têm como rocha armazenadora arenitos da Fm. Pirambóia. Apenas em uma das ocorrências (Jacutinga), a armazenadora é composta por arenitos da Fm. Tatuí. Entre as ocorrências visitadas, a estrutura sedimentar mais comum é a estratificação cruzada de médio e grande porte.

As principais feições estruturais presentes na área são os altos estruturais de Anhembi (SOARES 1974) e Carlota Prenz (Figura 2A), além do sistema linear Torre de Pedra. Os altos estruturais caracterizam-se pela presença de uma janela estratigráfica na qual afloram rochas da Fm. Teresina (Permiano) em meio a rochas da Fm. Pirambóia (Triássico). Mais de 90 \% das ocorrências estudadas estão espacialmente próximas destas estruturas.

O estabelecimento de analogias entre a geologia de áreas da borda da bacia e de suas porções mais profundas pode auxiliar a prospeç̧ão de hidrocarbonetos. Apesar do grande desenvolvimento tecnológico na aquisição de dados sísmicos, as soleiras e diques de rochas ígneas ainda são um impedimento à obtenção de respostas de refletores sísmicos profundos. Desse modo, a possibilidade de detecção de estruturas geológicas com base em feições geomórficas e o entendimento de sua relação com os processos de migração e acumulação é importante ferramenta em um programa exploratório para auxiliar o estudo de plays petrolíferos a baixo custo.

O principal objetivo deste trabalho é a deteç̧ão de estruturas relacionadas à gênese dos arenitos asfálticos a partir do estudo de sua expressão na superfície do terreno. Busca-se também o entendimento da relação entre estas estruturas e os processos de migração e acumulação de hidrocarbonetos. O procedimento metodológico foi baseado na intepretação morfoestrutural da rede de drenagem e de imagens de sensoriamento remoto. 


\section{ASPECTOS GEOMORFOLÓGICOS E OCORRÊNCIAS DE ARENITOS ASFÁLTICOS}

O posicionamento das estruturas geológicas, a história geológica da área de estudo e a gênese das ocorrências têm reflexos detectáveis nos aspectos geomorfológicos da área de afloramento. Toda a área de estudo está inserida na Unidade Morfoestrutural da Bacia Sedimentar do Paraná (ROSS \& MOROZ 1997). De modo geral, as ocorrências de arenitos asfálticos localizam-se em áreas cujas cotas topográficas variam de 400 até 700 metros (Figura 2B). A área de estudo situa-se no Planalto Ocidental Paulista (Planalto Centro Ocidental e Planalto Residual de Botucatu) e Depressão Periférica Paulista (Depressão do Médio Tietê e Depressão do Paranapanema). Relevos escarpados na forma de cuestas marcam o contato entre depressão e planalto. As ocorrências de arenito asfáltico encontram-se preferencialmente nas áreas deprimidas, seja na região do Médio Tietê ou na região do Vale do Paranapanema (Figura 2B).

Na depressão do Paranapanema e Médio Tietê os padrões de drenagem são paralelos e, também, dendríticos, freqüentemente com alinhamentos de drenagem de direções NE e NW, relacionados diretamente ao padrão de fraturamento da Bacia do Paraná. Nas áreas de ocorrência de arenito asfáltico as formas de relevo são de colinas de topo convexo, aplanado ou tabular. Localmente, observam-se ocorrências próximas a fundo de vales e em encostas. Não foram observadas ocorrências em topos de morros.

Além dos elementos geológicos relacionados à formação e deformação da Bacia do Paraná, os processos denudacionais posteriores têm importância na exposição das ocorrências de arenito asfáltico; todos estes elementos, sejam geológicos ou geomorfológicos, devem ser considerados para o entendimento da sua gênese.

Vários autores citam os processos erosionais instalados na Bacia do Paraná e regiões circunvizinhas e os relacionam às superfícies de aplainamento ao longo do tempo geológico (KING 1956, ALMEIDA 1964, AB'SABER 1969). Sem dúvida, estes processos erosionais iniciados no final do Cretáceo e posteriores denudaram as coberturas geológicas que encobriam as acumulações de hidrocarbonetos da Fm. Pirambóia.

Para KING (1956), a discordância do Cretáceo em relação às lavas triássicas (Fm. Serra Geral,
Cretáceo), ao arenito Botucatu e às formações permianas e carboníferas, representa a superfície Gondwana, que é posteriormente modificada pela superfície Pós-Gondwana. Segundo esse autor, esta superfície forma uma zona de terrenos acidentados entre um remanescente da superfície Gondwana e a superfície Sul-Americana. Finalmente, a superfície Sul Americana foi esculpida durante um longo período no decorrer do Terciário Inferior e atingiu grande uniformidade e aplainamento (KING 1956). Ainda segundo esse autor, esta superfície constitui um planalto dissecado e recobre a maior parte do leste paulista. Vários autores têm atribuído à superfície Sul-Americana idades que vão desde o Eoceno ao Plioceno. KING (1956) admite idades de aplainamento desta superfície no intervalo entre o fim do Cretáceo e o início do Mioceno.

Segundo ALMEIDA (1964), há evidências da presença de uma antiga superfície de erosão senil que nivelou e esculpiu estruturas pré-cambrianas no Estado de São Paulo. Em relação a esta antiga superfície, AB'SABER (1954 apud ALMEIDA 1964) afirma que há simultaneidade entre a sedimentação cretácea da Bacia do Paraná e processos de pediplanação, dos quais resultaria a superfície chamada de Japi. Segundo ALMEIDA (1964), pode se ter certeza que a superfície do Japi é anterior à sedimentação pliocênica das bacias do Paraíba e São Paulo.

\section{ARENITOS ASFÁLTICOS DA BORDA LESTE DA BACIA DO PARANÁ, SP}

As ocorrências de arenitos asfálticos são compostas principalmente por arenitos da Fm. Pirambóia, de granulometria média e de boa permeabilidade/ porosidade, os quais foram preenchidos secundariamente por hidrocarbonetos.

A gênese das ocorrências encontradas na área está relacionada ao sistema petrolífero Irati-Pirambóia (ARAÚJO et al. 2000). A rocha geradora é composta pelos folhelhos negros da Fm. Assistência, Subgrupo Irati (HACHIRO et al. 1993). Segundo ARAÚJO (2003), o modelo genético destas ocorrências relaciona a geração de óleo à intrusão de soleiras cretáceas da Fm. Serra Geral nos folhelhos negros Irati,(Permiano), migração por falhas e paredes de diques e acumulação nos arenitos Pirambóia (Triássico). Fácies de interduna e fluviais da Fm. Pirambóia agiram como armadilhas horizontais, enquanto os diques básicos agiram como armadilhas verticais. 
Distinguem-se duas regiões principais de ocorrências de arenitos asfálticos na borda leste da Bacia do Paraná. Uma região ao norte da cuesta de Botucatu (Planalto Residual de Botucatu), chamada “área Anhembi” ou “Alto Estrutural de Anhembi”, localizada na depressão do Rio Tietê, nas cercanias da cidade de Anhembi, junto à represa de Barra Bo- nita (Figura 2B). A outra região localiza-se ao sul do Planalto de Botucatu, na região denominada "área Jacu” ou "área da estrutura do Jacu”. Esta área localiza-se na depressão do Rio Paranapanema, com ocorrências nas cercanias das cidades de Guareí, Angatuba e junto à Rodovia Castelo Branco, no município de Bofete (Figura 2B).
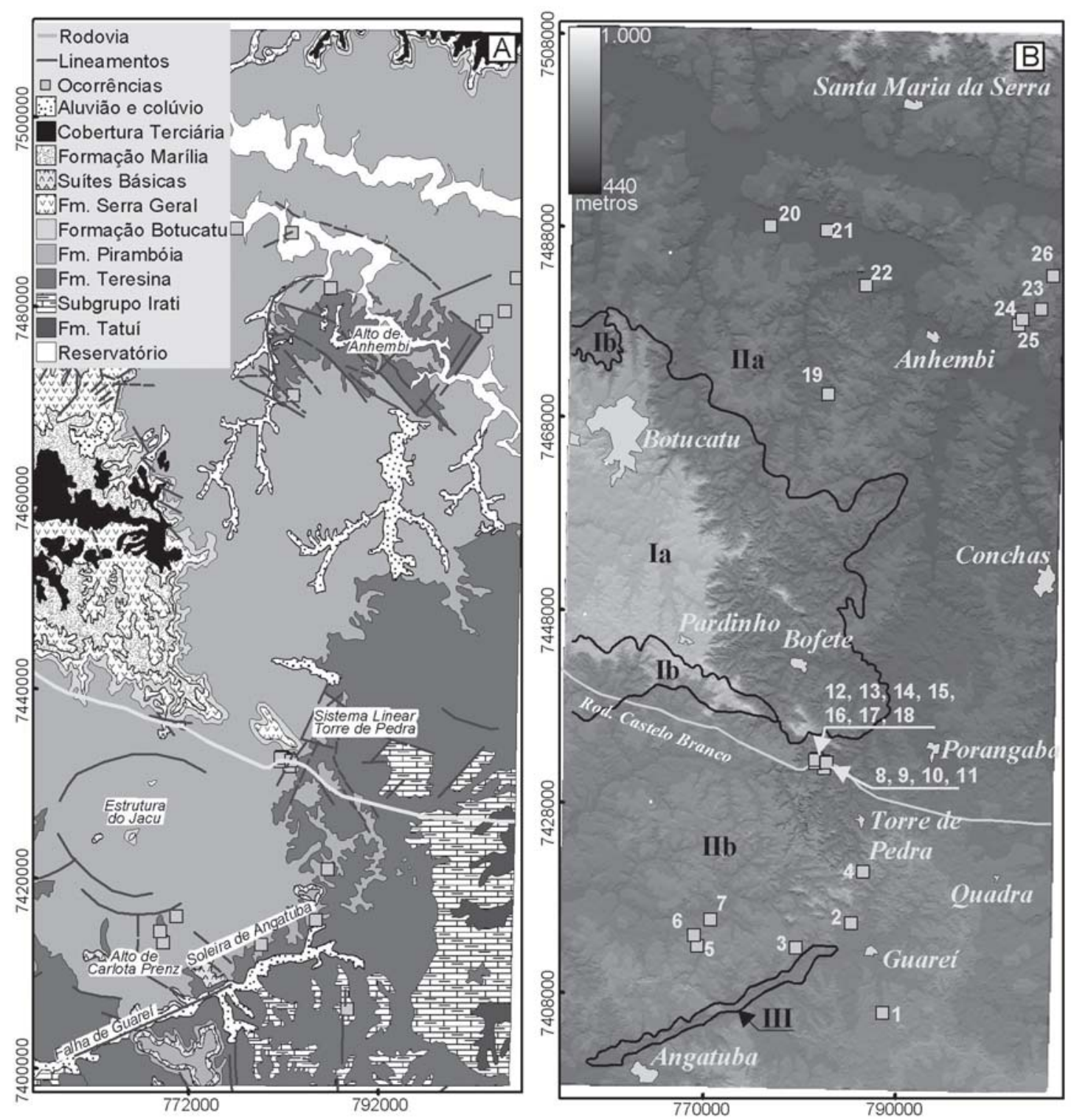

FIGURA 2 - (A) Mapa geológico da área de estudo (DAEE-UNESP, 1984); (B) modelo numérico de terreno com a localização das ocorrências de arenitos asfálticos: (1) Jacutinga; (2) Nhaíva; (3) Itatigue; (4) Bairro Quebra; (5) Sobar; (6) Sobar II; (7) Sobar III; (8) Morro do Bofete; (9) Morro do Bofete II; (10) Morro do Bofete III; (11) Morro do Bofete IV; (12) Estrada da Mina; (13) Estrada da Mina II; (14) Bairro da Mina; (15) Bairro da Mina II; (16) Bairro da Mina III; (17) Fazenda São Jorge; (18) Fazenda São Jorge II; (19) Piapara; (20) Porto Martins; (21) Volta Grande; (22) Braço da Represa; (23) Betumita; (24) Moquém; (25) Moquém II; (26) Fazenda Ribeirão Claro. Esboço geomorfológico da área de estudo, com os principais compartimentos geomorfológicos (ROSS \& MOROZ 1997): (Ia) Planalto Residual de Botucatu; (Ib) Planalto Centro Ocidental; (IIa) Depressão do Médio Tietê; (IIb) Depressão do Paranapanema; (III) Planícies Fluviais. Coordenadas UTM em metros - SAD69, M.C.51. 
A estrutura do Jacu (Figura 3) é uma morfoestrutura com um padrão anelar de drenagem, diâmetro de 20 km (rios Santo Inácio e Capivari) e com padrão radial externo de drenagem (Rio Antônio José e Ribeirão da Restinga). Observa-se no Modelo Numérico de Terreno (MNT) o padrão NWNE de estruturas lineares (Figura 3). Um elemento importante na área Jacu é a presença de altos estruturais com afloramento de rochas permianas em meio a rochas triássicas. Estas estruturas estão provavelmente relacionadas a zonas de fraqueza, como falhamentos regionais. Nesta área, a estrutura geológica mais proeminente é o Alto Estrutural de Sobar, também chamado de Domo de Carlota Prenz ou Alto Estrutural de Carlota Prenz (STILL 1952, apud SOARES 1974), que ocorre na porção sul da estrutura do Jacu (Figura 3). Nesta estrutura, os siltitos Teresina afloram em dois corpos quilométricos de forma elíptica, cujo eixo maior tem direção aproximada N-S.

A área do Alto Estrutural de Anhembi é caracterizada pelo afloramento de rochas permianas em meio a rochas triássicas. As cotas topográficas, na área, variam de 450 a 600 m e o contato entre a Fm. Pirambóia e Teresina ocorre em cotas variáveis entre 460 até $545 \mathrm{~m}$, de acordo com levantamentos de campo. A estrutura de Anhembi caracteriza-se por um eixo maior de direção N50W e falhas de direção N, NW e NE, as quais separam os arenitos da Fm. Pirambóia dos siltitos roxos da Fm. Teresina. Esta estrutura pode ser compartimentada em três blocos (PETROBRÁS 1971, apud FRANZINELLI 1972), chamados Alto de Anhembi, na porção norte da estrutura, Alto de Anhembi Sul, na porção intermediária, e Alto de Piapara, na porção sudoeste. A região ao

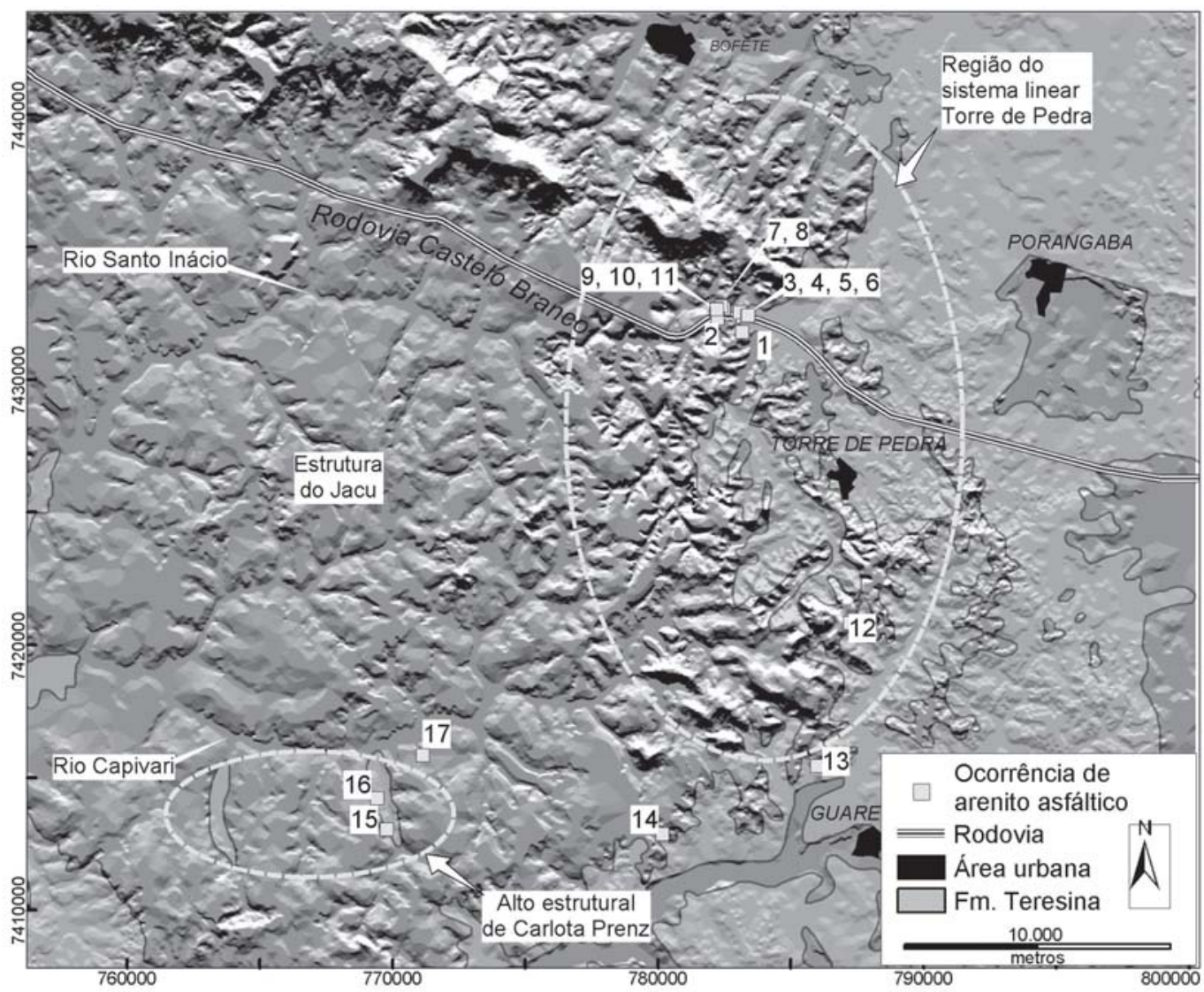

FIGURA 3 - Área Jacu com distribuição das ocorrências de arenito asfáltico em modelo numérico de terreno (MNT), iluminação de norte com $30^{\circ}$ de inclinação. Ocorrências: (1) Fazenda São Jorge; (2) Fazenda São Jorge II; (3) Morro do Bofete; (4) Morro do Bofete II; (5) Morro do Bofete III; (6) Morro do Bofete IV; (7) Estrada da Mina; (8) Estrada da Mina II; (9) Bairro da Mina; (10) Bairro da Mina II; (11) Bairro da Mina III; (12) Bairro Quebra; (13) Nhaíva; (14) Itatigue; (15) Sobar; (16) Sobar II; (17) Sobar III. Coordenadas UTM em metros - SAD69, M.C.51. 
noroeste da cidade de Anhembi é caracterizada por uma expressiva anomalia de drenagem, na forma de semicircunferência, formada pelo Rio Alambari e por um braço da Represa de Barra Bonita. Nesta anomalia de drenagem também são observadas drenagens radiais como o Ribeirão Água do Monjolo e o Córrego Barreirinho (Figura 4). Observa-se no MNT o padrão principal NW de estruturas lineares e subordinadamente de feições NE, além da anomalia de drenagem citada anteriormente.

\section{MATERIAIS E MÉTODOS}

Para a interpretação estrutural foram utilizadas oito cartas topográficas 1:50.000 do IBGE (Barra Bonita, Santa Maria da Serra, Botucatu, Anhembi, Bofete ou Pardinho, Conchas, Angatuba e Guareí) e imagens de sensoriamento remoto Landsat 7 ETM+, de 29 de novembro de 1999, com seis bandas espectrais com 30 metros de resolução e uma banda pancromática com 15 metros de resolução. A partir das cartas topográficas, a rede de drenagem foi digitalizada e a seguir completada com informações da banda pancromática. A interpretação geológica e morfoestrutural foi baseada nos procedimentos metodológicos de SOARES \& FIORI (1976), MATTOS et al. (1982), VENEZIANI (1987) e CREPANI (1987). A interpretação morfoestrutural consistiu no reconhecimento dos padrões de drenagem, anomalias de drenagem e suas feições retilíneas (alinhamento de drenagem) e, finalmente, a partir destes elementos, o traçado de flexuras de terreno. Os produtos obtidos foram o mapa morfoestrutural, o mapa de lineamentos estruturais, mapas de densidade de fraturamento e rosetas de direção de fraturamento, segundo tipos litoestratigráficos.

Os dados foram georreferenciados e organizados em um sistema de informação geográfica (SIG). O SIG foi utilizado para a análise da rede de drenagem e das imagens de sensoriamento remoto via monitor e para o cruzamento das ocorrências de arenito asfáltico conhecidas com os elementos in-

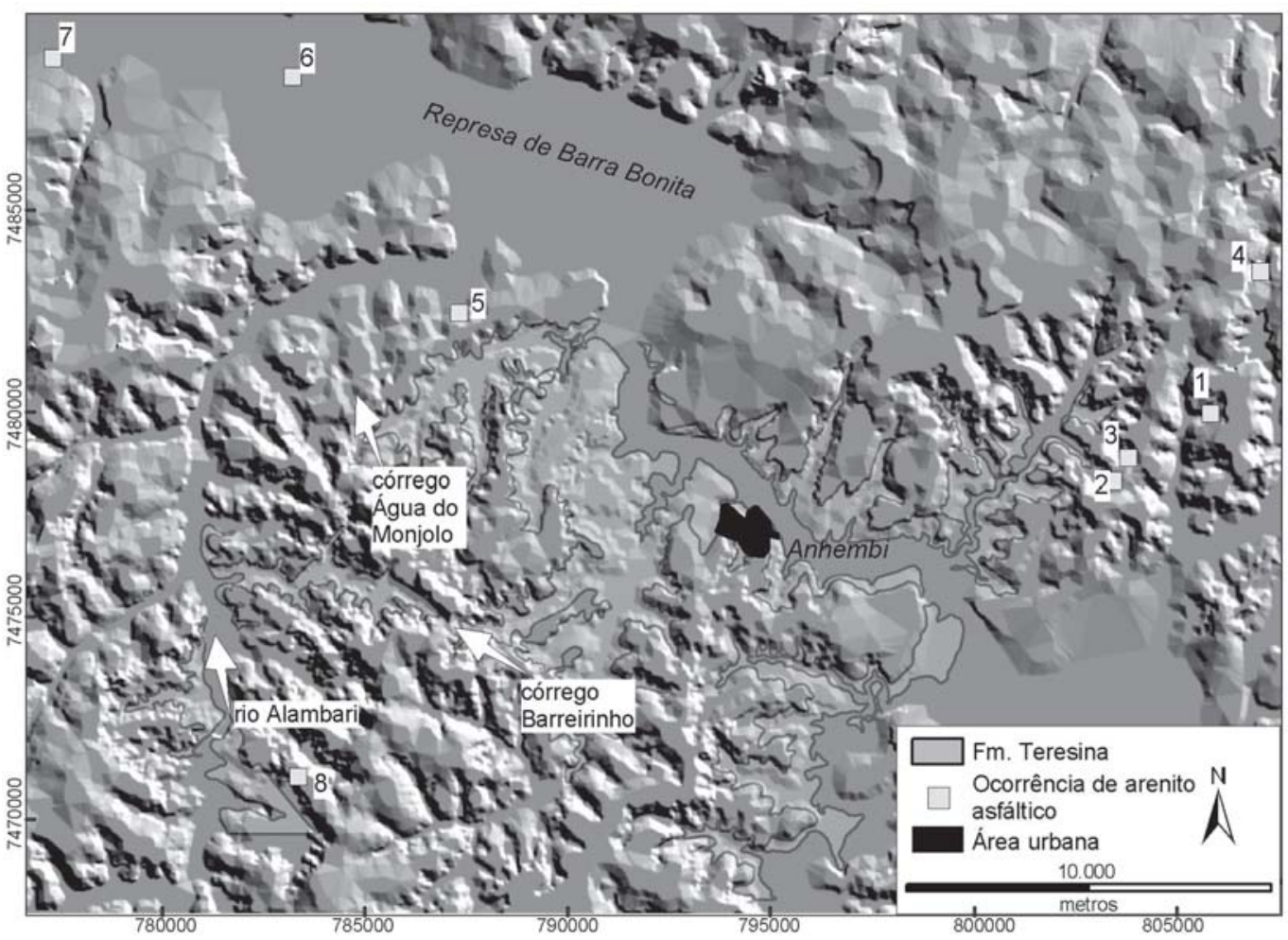

FIGURA 4 - Área Anhembi, com distribuição das ocorrências de arenito asfáltico em modelo numérico de terreno (MNT), iluminação de norte com $45^{\circ}$ de inclinação. Ocorrências: (1) Betumita; (2) Moquém; (3) Moquém II; (4) Fazenda Ribeirão Claro; (5) Braço da Represa; (6) Volta Grande; (7) Porto Martins; (8) Piapara. Coordenadas UTM em metros - SAD69, M.C.51. 
terpretados. O procedimento de organização dos dados foi feito em um SIG, mas o traçado dos mapas de morfoestruturas e lineamentos foi manual, em papel transparente, e posteriormente digitalizado.

\subsection{Interpretação morfoestrutural}

O termo morfoestrutura é definido como uma "feição topográfica maior que coincide com ou é uma expressão de estrutura geológica ou que é formada diretamente por movimentos tectônicos. É produzida pela interação de forças endógenas $e$ exógenas, sendo predominante a forma” (Bates \& Jackson, 1987). Segundo GONTIJO (1999), o termo morfoestrutura deve ser empregado quando a elaboração das formas de relevo se processa sob controle tectônico passivo, ou seja, as formas de relevo não estão necessariamente relacionadas à tectônica ativa (neotectônica).

Segundo MATTOS et al. (1982), o termo morfoestrutura define uma estrutura presumida, identificada a partir da análise e interpretação de informações basicamente de relevo e drenagem, caracterizada por zonas anômalas dentro de um padrão geral de distribuição dos elementos de relevo e drenagem (Figura 5).

O mapeamento morfoestrutural procurou, a partir dos padrões de drenagem (assimetria e tropia) e dos lineamentos estruturais, traçar as flexuras do terreno derivadas de processos geológicos (Figura 6). É importante ressaltar que, para a área de estudo, devido a sucessivas reativações de estruturas antigas e a eventos tectônicos expressivos podem ser reconhecidas feições correlacionáveis ao embasamento da bacia e à Reativação PósPaleozóica.

O traçado, a partir da geometria de drenagem, permite visualizar a conformação estrutural da área e indicar as regiões de alto e baixo estrutural. As linhas traçadas podem ser cotadas com valores arbitrários (Figura 6), que podem ser usados para construir um modelo numérico de terreno, o qual permite uma melhor visualização da conformação estrutural interpretada. É importante ressaltar que o detalhe morfoestrutural depende da escala de trabalho adotada, neste caso 1:100.000.

Uma etapa importante na interpretação morfoestrutural em bacias sedimentares é reconhecer as formas anômalas de drenagem. Segundo CREPANI (1987), a interpretação das formas anômalas da rede de drenagem e dos arranjos formados por diferentes combinações entre elas permite que se infira o seu significado geológico, uma vez que a

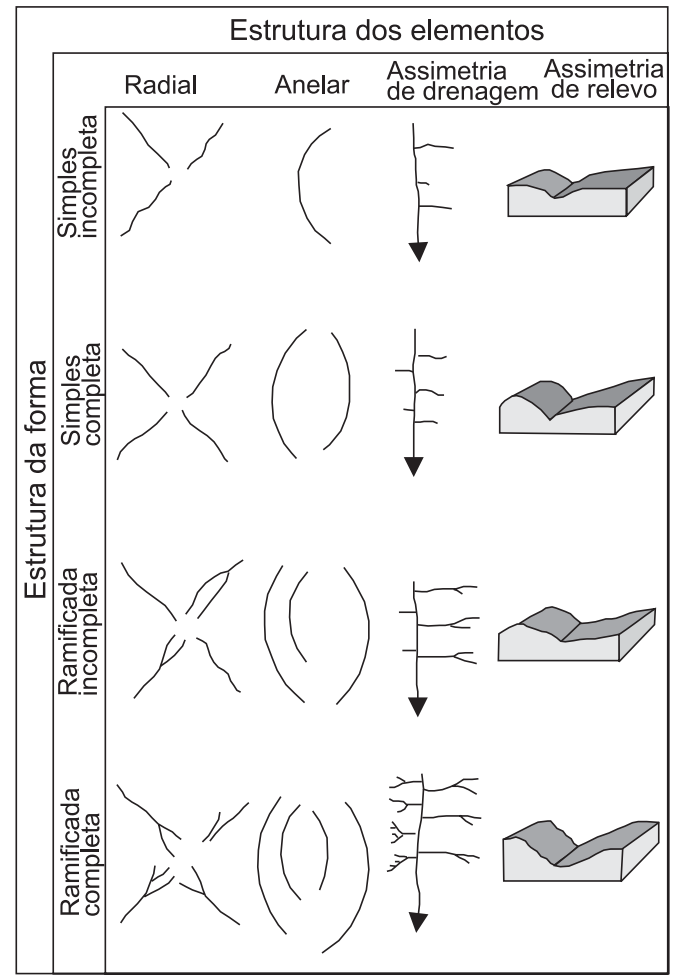

FIGURA 5 - Classificação das formas anômalas de drenagem (Modificado de MATTOS et al. 1982).

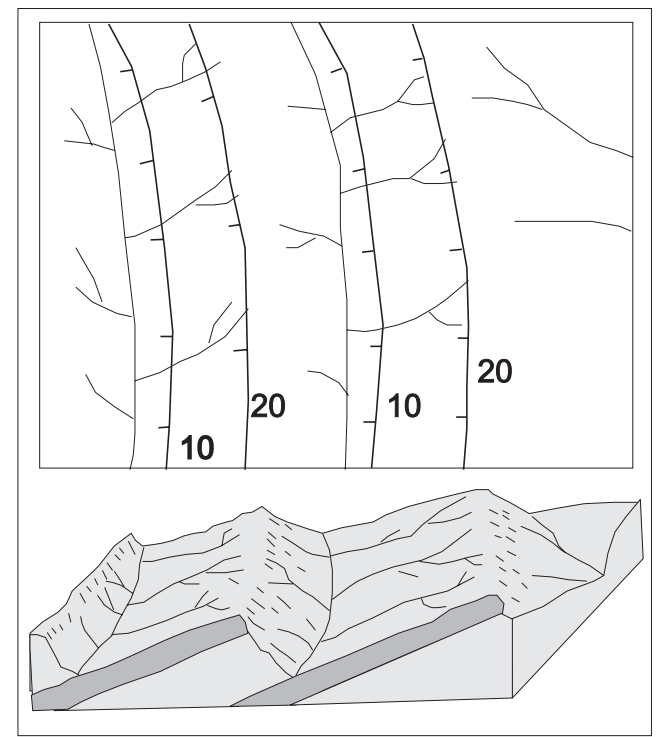

FIGURA 6 - Esquema de traçado de morfoestruturas (linhas pretas cotadas, traços indicam direção do mergulho). 
intensidade de estruturação dessas formas representa o grau de controle estrutural a que estão submetidas. Dessa forma, segundo o autor, as anomalias morfoestruturais são constituídas pelo arranjo simultâneo de formas anelares, radiais e assimetrias de drenagem como produto de condicionamento da rede hidrográfica por estruturas de sub-superfície de bacias sedimentares. Tais estruturas caracterizamse por flexuras anelares ou elípticas nas camadas, associadas a mergulhos divergentes, no caso de domos, ou convergentes, no caso de depressões estruturais.

Em seguida, foram retiradas as feições retílineas de drenagem. Finalmente, procedeu-se à interpretação das feições lineares de relevo (positivas) e de drenagem (negativas).

Ao sobrepor os lineamentos interpretados com as anomalias de drenagem e traços de camadas procura-se definir o limite entre os blocos altos e baixos. Além disso, os lineamentos influenciam na definição dos desenhos das anomalias morfoestruturais, seja ao truncar ou deslocar a anomalia, ao fechar ou limitar a área da anomalia, ou mesmo, ao inverter o mergulho regional ou local. O mapa resultante (Figura 7B) está na forma de linhas não cotadas representando as flexuras do terreno, de modo que quanto maior a densidade de curvas não cotadas melhor será a definição dos limites entre blocos. Para melhor visualização, estas linhas podem ser interpoladas gerando um modelo numérico de terreno.

\subsection{Lineamentos estruturais}

O termo lineamento foi originalmente definido por HOBBS (1912, apud VENEZIANI 1987) para caracterizar as relações espaciais de feições, tais como cristas, bordas de áreas elevadas, alinhamentos de contatos geológicos ou tipos petrográficos, ravinas ou vales, e fraturas ou zonas de falhas visíveis como tais. Segundo VENEZIANI (1987), pode ser empregado como designativo de feições definidas por alinhamentos de relevo e drenagem, os quais englobam as formas definidas por Hobbs.

A distinção entre lineamentos estruturais e falhamentos, na interpretação dos produtos de sensoriamento remoto, é necessária devido aos seguintes fatores (VENEZIANI 1987):

- os lineamentos não se restringem ao desenvolvimento de apenas um tipo de movimento tectônico ao longo de toda sua extensão ou durante o decorrer dos diferentes ciclos ou fases tectônicas que afetaram uma determinada área;
- uma zona de falha pode dar origem a diversos lineamentos paralelos a sub-paralelos, ou viceversa, isto é, várias fraturas associadas a uma zona de falha podem dar origem a apenas um lineamento distinguível nos produtos de sensoriamento remoto.

\subsection{Zonas de juntas}

O termo fratura, segundo RAMSAY \& HUBER (1987), é definido como um plano de ruptura onde a coesão da rocha foi perdida; este plano pode corresponder a juntas ou falhas.

Os elementos de drenagem fortemente estruturados (disposição regularmente ordenada), retilíneos ou em arco, denominam-se, segundo SOARES \& FIORI (1976), lineações de drenagem e são interpretados como traços de fratura. Os traços de fratura correspondem a zonas de concentração de juntas.

O termo “conjunto de zonas de juntas" é definido por PLICKA (1974) como uma série de zonas de juntas paralelas entre si e com uma gênese comum.

Características importantes das zonas de juntas podem ser utilizadas na prospecção mineral (PLICKA 1974, NICKELSEN 1974):

- os conjuntos de zonas de juntas podem emergir de rochas mais antigas e se estender verticalmente através de rochas sobrejacentes mais novas;

- os padrões de fraturamento são cumulativos e persistentes.

Segundo VENEZIANI (1987), os conjuntos de zonas de juntas são feições geológicas de significado regional, independentes de variações litoestratigráficas locais e da atitude dos estratos, embora estes dois últimos fatores exerçam controle sobre a freqüência.

Baseando-se em metodologia de VENEZIANI (1987), a partir de um mapa com as curvas de isodensidade de fraturamento, pode-se interpretar um mapa de eixos de distribuição de fraturamentos na superfície. Segundo ALIYEV (1979), estes eixos representam direções de fraquezas precedentes à instalação dos sistemas de fraturas generalizadamente observados e, conseqüentemente, influem e favorecem um acréscimo na densidade de fraturamentos de gerações posteriores, ao longo dos mesmos.

$\mathrm{Na}$ interpretação realizada no presente estudo, os trechos retilíneos de canais de drena- 
gem foram considerados como elementos de interesse, já que as drenagens estabelecem-se preferencialmente sobre as linhas susceptíveis à maior erodibilidade, como as zonas de juntas e fraturas.

Utilizou-se um comprimento mínimo do traço igual a 3 mm para interpretação de feição retilínea na escala 1:250.000, o que equivale a $750 \mathrm{~m}$. Este valor visou a interpretação regional das zonas de fraturamento.

Analisou-se a freqüência de traços por área. O método de cálculo desta freqüência foi baseado na contagem do número de traços em uma grade regular de amostragem, considerando-se como padrão traços de, aproximadamente, mesmo comprimento. Segundo BEISL (1996), a grade regular de amostragem pode ser definida a partir do comprimento médio e desvio padrão das feições lineares extraídas das drenagens. No caso em estudo, o valor foi de $539 \pm 154 \mathrm{~m}$. Deste modo, a grade regular de amostragem poderia ter um valor de $700 \mathrm{~m}$. Contudo, este tamanho de grade mostrou-se inadequado para representar as diferenças de densidade de fraturamento. Assim, optou-se por aplicar diversos tamanhos de grade de amostragem, visando-se definir, empiricamente, o melhor tamanho de grade para a interpretação visual posterior. Utilizaram-se grades de 1500, 2000, 2500, 3000, $4000 \mathrm{~m}$ de lado, das quais a grade de $2500 \mathrm{~m}$ apresentou o melhor resultado. Para melhorar o aspecto final, foi feita uma reamostragem para uma grade de $500 \mathrm{~m}$. Com base na roseta dos traços de fratura interpretados a partir da rede de drenagem, definiram-se duas direções preferenciais de zonas de juntas, que são as seguintes: N45E e N45W. A partir destas direções, foi aplicada uma tolerância angular de $45^{\circ}$. Assim, foram gerados mapas de densidade de zonas de juntas de direções NW e NE.

\subsection{Lineamentos e zonas de juntas}

Conforme a metodologia apresentada por CREPANI (1987), na análise dos mapas de isofreqüência, consideram-se as seguintes observações:

- a quantidade de zonas de juntas aumenta em relação à proximidade de falhas, indicando uma associação genética e geométrica entre as falhas e os conjuntos de zonas de juntas;

- lineamentos antigos tendem a condicionar a freqüência das zonas de juntas formadas em regiões submetidas a processos de reativação.
Segundo VENEZIANI (1987), ao analisar as relações entre lineamentos e zonas de juntas, podese observar os seguintes aspectos:

- os feixes de zonas de juntas associam-se aos lineamentos mais expressivos de acordo com a verificação de PLICKA (1974);

- as direções dos feixes de zonas de juntas podem ser paralelas aos lineamentos, possivelmente indicando reflexos na superfície da propagação de falhamentos profundos com movimentação relativa vertical.

\section{RESULTADOS OBTIDOS}

\subsection{Lineamentos e morfoestruturas}

No mapa morfoestrutural (Figura 7B), os maiores valores (cinza escuro) correspondem a altos morfoestruturais e os menores valores (cinza claro) a baixos morfoestruturais.

Verifica-se a partir do mapa morfoestrutural, em termos regionais, que a área é composta por blocos homoclinais com mergulho para o norte (Figura 8). A porção sul da área de estudo, estrutura do Jacu, está em posição estrutural mais alta que a porção norte, Alto Estrutural de Anhembi. A área de estudo é dominada por estruturas NE e NW que se interceptam, como observado nas figuras 3, 4 e 7, gerando altos estruturais locais.

A área Jacu é caracterizada pela presença de uma anomalia de drenagem anelar central, um alto, circundado por baixos estruturais. Ao redor desta “casca de cebola” verifica-se a presença de altos estruturais de direções NW, NS e NE (Figuras 7B e 8). Sua origem estaria relacionada à disposição das intrusões da Fm. Serra Geral. Além disso, há de se considerar os fenômenos que condicionaram o padrão espacial das intrusões: interação das áreas de fraqueza do embasamento e eventos tectônicos jurássicos que romperam as estruturas anteriores. As ocorrências de arenitos asfálticos na área localizam-se, principalmente, nas porções intermediárias entre altos e baixos morfoestruturais (Figura 8). Estas regiões intermediárias são interpretadas como áreas de limite entre blocos tectônicos, onde estão instaladas estruturas relacionadas a áreas de fraqueza, como as falhas e intrusões básicas.

Na área Anhembi (Figura 8), nota-se a configuração de estruturas de direção NE na região de Piapara (altos e baixos morfoestruturais) e NW na região da Represa de Barra Bonita (baixo 
morfoestrutural). Notou-se, a partir de fotografias aéreas e de imagens de sensoriamento remoto, que algumas ocorrências também estão relacionadas a morfoestruturas localizadas precisamente em regiões intermediárias entre altos e baixos estruturais. Entretanto, esta observação não é clara no mapa morfoestrutural devido ao relevo arrasado em parte da região e à cobertura sedimentar terciária, que dificultou a interpretação relacionada principalmente a fenômenos mais antigos.
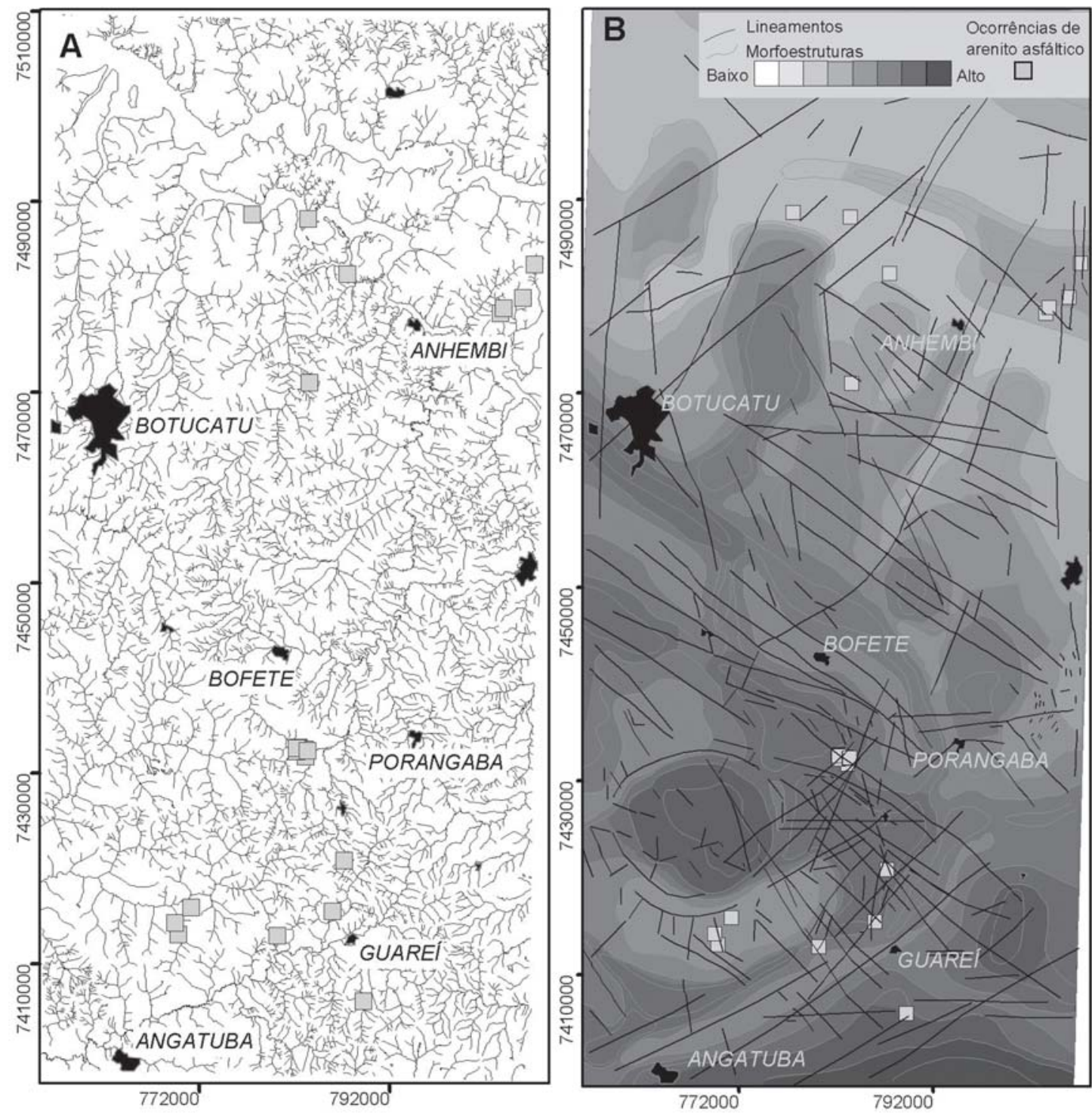

FIGURA 7 - (A) Rede de drenagem digitalizada a partir de cartas topográficas 1:50.000 e complementada com imagem de satélite; (B) Lineamentos interpretados a partir da rede de drenagem e imagem de satélite sobreposto ao mapa morfoestrutural intepretado a partir da rede de drenagem digitalizada e lineamentos. 
almente aquelas com fraturamento na mesma direção de deslocamento do movimento. A geração de falhas está relacionada a antigas zonas de fraqueza incluindo as estruturas do embasamento, eventos permianos e a Reativação Pós-Paleozóica. É inferido que as falhas transportaram hidrocarbonetos por dezenas de metros verticalmente e poucos metros lateralmente.

\subsection{Zonas de juntas}

Em termos regionais, nota-se que a maior densidade de zonas de juntas localiza-se na porção sul da área de estudo (Figura 9). Esta disposição pode ser interpretada como resultante da cobertura sedimentar terciária mais ampla na região da represa de Barra Bonita, norte da área de estudo, que dificulta a interpretação de feições retilíneas de drenagem.Conclui-se também que a porção sudoeste da área de estudo teria sido mais afetada pela tectônica do Arco de Ponta Grossa, havendo uma diminuição deste fenômeno para o norte.

A Zona de Falha de Jacutinga, o lineamento do Tietê e o lineamento Barra Bonita-Itu (Figura 1) têm respostas pouco evidentes no mapa de densi- dade de zonas de juntas, representadas por valores médios a altos, alinhados NE. Já a região do alinhamento do Paranapanema, Alto de Carlota Prenz, Soleira de Angatuba e Falha do Rio Guareí (Figura 2) apresentam padrões de alta densidade de zonas de juntas. Deste modo, o domínio de altos valores de densidade, na região sul da área de estudo, é interpretado como reflexo da tectônica juro-cretácea na forma de falhas e intrusões de rochas básicas.

Na tabela 1 observam-se os valores de densidade de zonas de juntas para as ocorrências de arenitos asfálticos, considerando o conjunto total e também as densidades segundo as direções NW e NE. De modo, geral as ocorrências localizam-se em áreas de valores intermediários de densidade.

A partir do conjunto total das zonas de juntas, foi feita uma separação baseada na estratigrafia regional da área. Esta separação teve como objetivo a pesquisa de fraturas associadas a eventos geológicos relacionados a diversos períodos e verificar a relação destes eventos com o tempo de migração dos hidrocarbonetos e também com o processo denudacional. Dessa forma, utilizou-se o mapa geológico compilado de DAEE/UNESP (1984) na escala

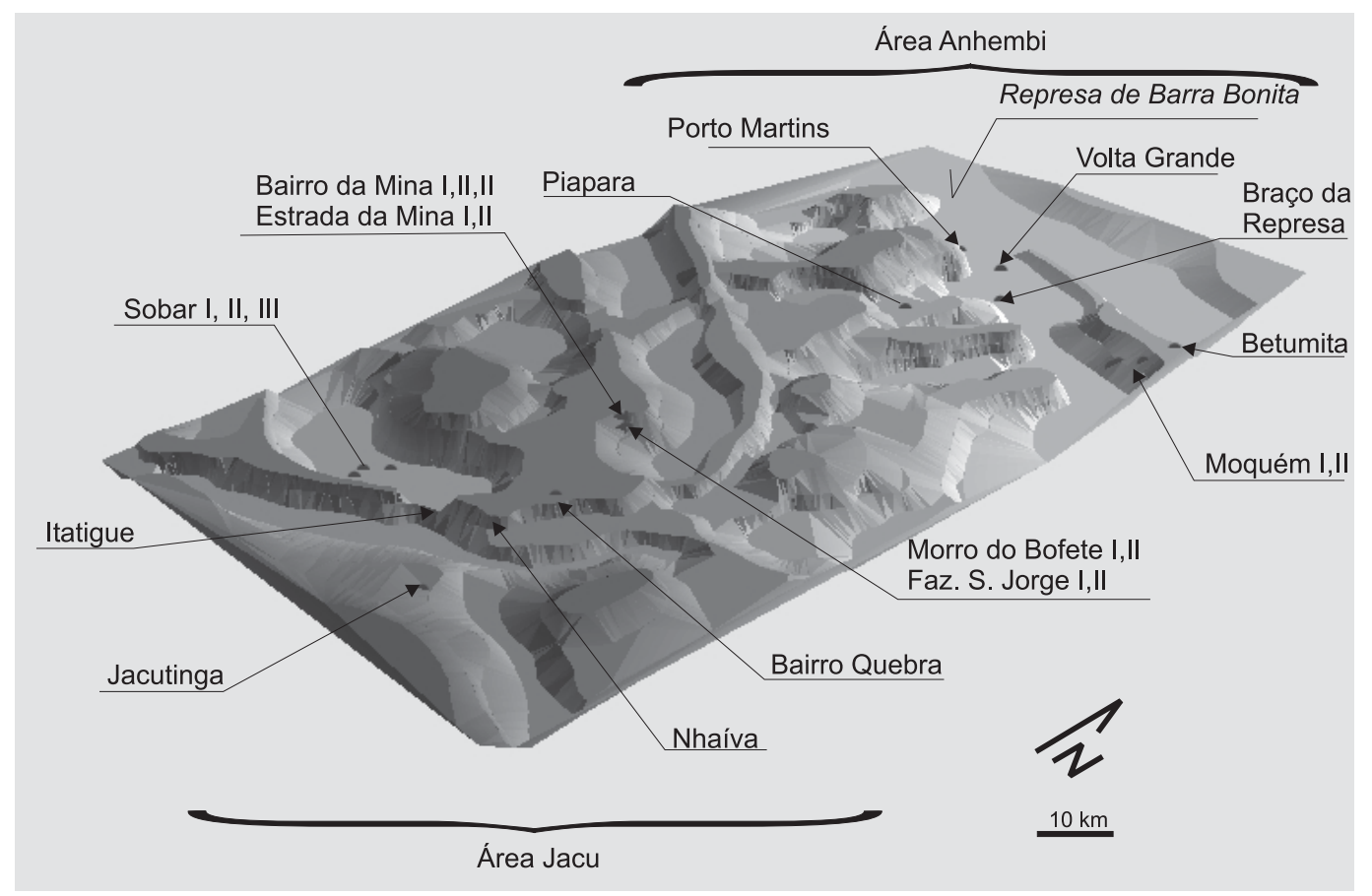

FIGURA 8 - Modelo numérico da interpretação morfoestrutural em perspectiva, iluminação de norte. Ocorrências de arenito asfáltico indicadas pelas setas. 

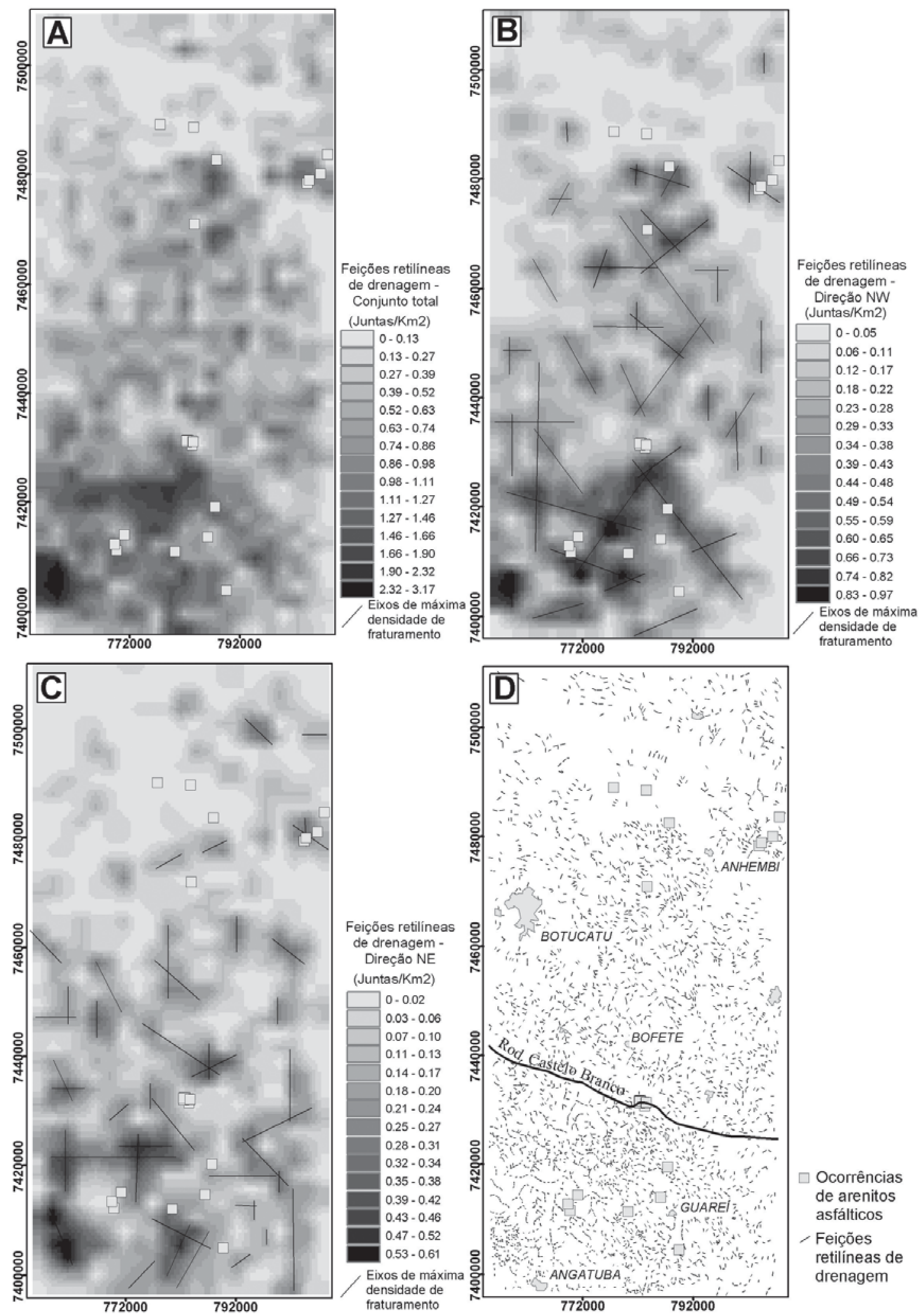

$\square$ Ocorrências

de arenitos

asfálticos

Feições

retilineas de drenagem

FIGURA 9 - Feições retilíneas de drenagem interpretadas e mapas de densidade; (A) Conjunto total; (B) direção NW; (C) direção NE; (D) feições retilíneas de drenagem. Coordenadas UTM em metros - SAD69, M.C.51. 
1:250.000 para a separação das áreas de afloramentos de rochas do Permiano ao Quaternário. A separação das zonas de juntas foi feita segundo diferentes tipos litológicos/estratigráficos como pode ser visto na tabela 2 e figura 10 . O resultado desta separação de zonas de juntas por tipos litoestratigráficos pode ser observado nas figuras onde se apresentam as rosetas (Figuras 11 e Figura 12) e na tabela 3.

Para testar a consistência do método empregado foi feita a separação das feições retilíneas de drenagem de uma região no sul da área de estudo (área Jacu). A roseta gerada para esta área foi comparada com a roseta da área total (Figura 11 A e B). Verificou-se que não há diferença no padrão de zonas de juntas da região sul em relação a toda área de estudo.

As rosetas das feições de rochas permianas (Permiano 1, Figura 12A) demonstram o acúmulo de estruturas ao longo do tempo geológico. Ao final do Permiano (Permiano 2, Figura 12B) é possível, apesar dos ruídos nos dados, verificar a presença marcante de estruturas NW assim como ao longo do Triássico-Jurássico (Figura 12C) e Jurássico-Cretáceo (Figura 12D). Apesar do predomínio da direção NW, não é desprezível a alta freqüência de estruturas NE, que em conjunto com os eixos de máxima freqüência de fraturamento demonstra o papel condicionante das estruturas do embasamento, principalmente quando se observa a roseta do início do Permiano (Figura 12A) e de toda a área de estudo (Figura 11A). De modo geral, fraturamentos NW, verificados principalmente a partir do Triássico (Figura 12C e 12D) ajudam a confirmar a importância da Ativação PósPaleozóica na gênese das ocorrências de arenito asfáltico.

TABELA 1 - Ocorrências de arenitos asfálticos e valores de densidade de zonas de junta. (Densidade de zonas de juntas: ocorrências $/ \mathrm{km}^{2}$ ).

\begin{tabular}{lccc}
\hline Ocorrência & Conjunto total & NW & NE \\
\hline Bairro da Mina & 0.47 & 0.21 & 0.05 \\
Bairro da Mina II & 0.47 & 0.21 & 0.05 \\
Bairro da Mina III & 0.47 & 0.21 & 0.05 \\
Bairro Quebra & 1.16 & 0.51 & 0.13 \\
Betumita & 0.76 & 0.16 & 0.18 \\
Braço da Represa & 0.69 & 0.43 & 0.00 \\
Estrada da Mina & 0.47 & 0.21 & 0.05 \\
Estrada da Mina II & 0.47 & 0.21 & 0.05 \\
Fazenda Ribeirão Claro & 0.14 & 0.08 & 0.04 \\
Fazenda São Jorge & 0.29 & 0.20 & 0.02 \\
Fazenda São Jorge II & 0.52 & 0.21 & 0.04 \\
Itatigue & 1.00 & 0.45 & 0.27 \\
Jacutinga & 0.55 & 0.17 & 0.10 \\
Moquém & 0.90 & 0.28 & 0.22 \\
Moquém II & 1.02 & 0.31 & 0.26 \\
Morro do Bofete & 0.29 & 0.19 & 0.03 \\
Morro do Bofete II & 0.29 & 0.19 & 0.03 \\
Morro do Bofete III & 0.29 & 0.19 & 0.03 \\
Morro do Bofete IV & 0.29 & 0.19 & 0.03 \\
Nhaiva & 0.48 & 0.21 & 0.11 \\
Piapara & 0.41 & 0.36 & 0.03 \\
Sobar & 1.12 & 0.53 & 0.07 \\
Sobar II & 0.98 & 0.38 & 0.04 \\
Sobar III & 0.58 & 0.24 & 0.17 \\
Volta Grande & 0.07 & 0.03 & 0.00 \\
Valor médio na área de estudo & 0.57 & 0.25 & 0.08 \\
\hline
\end{tabular}


TABELA 2 - Tipos litoestratigráficos utilizados na separação das zonas de juntas.

\begin{tabular}{ll}
\hline Litoestratigrafia & Nome da classe \\
\hline $\begin{array}{l}\text { Depósitos de cimeira, Fm. } \\
\text { Rio Claro, colúvios e aluviões }\end{array}$ & Coberturas \\
Suítes Básicas, Fm. & Jurássico/ \\
Serra Geral, Fm. Marília & Cretáceo \\
Fm. Pirambóia, Fm. Botucatu & $\begin{array}{l}\text { Triássico/ } \\
\text { Jurássico }\end{array}$ \\
Fm. Teresina & Permiano 2 \\
Subgrupo Irati, Fm. Tatuí & Permiano 1 \\
\hline
\end{tabular}

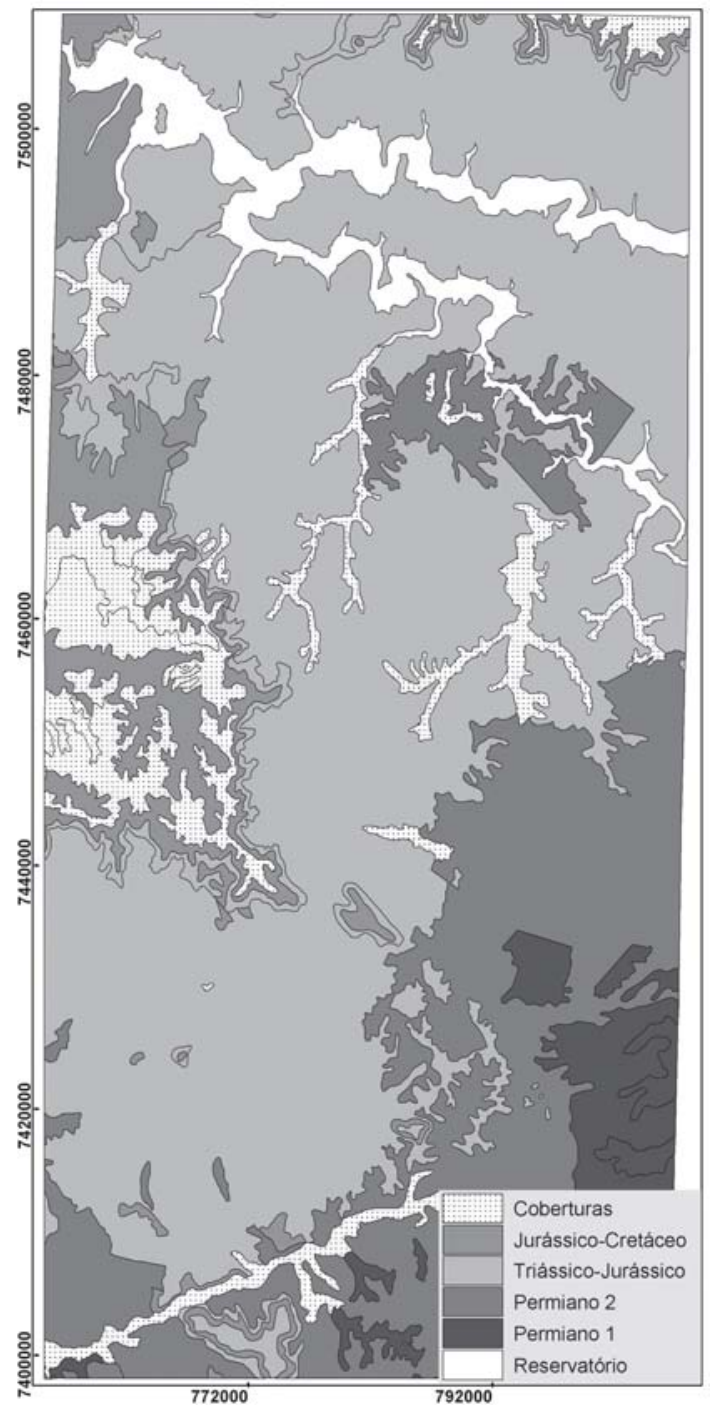

FIGURA 10 - Mapa com divisão estratigráfica utilizada para separação de juntas (modificado de DAEE/UNESP, 1984).

\section{DISCUSSÃO E CONCLUSÕES}

Estruturalmente, de sul para norte, a área de estudo é caracterizada por uma série de blocos altos, aparentemente homoclinais, com mergulhos suaves para o norte e abruptos na porção sul do bloco. Existem ocorrências de arenitos asfálticos associadas às zonas intermediárias e de baixos morfoestruturais. Na porção norte da área, as ocorrências de Porto Martins, Volta Grande, Betumita/ Moquém e Piapara estão associadas às zonas de baixo morfoestrutural ao redor do Alto Estrutural de Anhembi, cuja direção principal é NW. As ocorrências na porção sul da área Sobar, Itatigue, Nhaíva e Morro do Bofete encontram-se em áreas intermediárias entre altos e baixos morfoestruturais. A porção sul é caracterizada por um alto morfoestrutural, uma feição de forma anelar e diâmetro aproximado de 20 $\mathrm{km}$. Seu limite sul é marcado pela presença de falhamentos radiais, do domo de Carlota Prenz, pela soleira de Angatuba e pelo falhamento do Rio Guareí de direção NE. Seu limite norte é marcado pela presença de falhamentos radiais e pela Serra de Botucatu, além de falhamentos de direção NW.

TABELA 3 - Feições lineares de drenagem por tipo litoestratigráfico.

\begin{tabular}{lcc}
\hline Nome da classe & $\begin{array}{c}\text { Vetor } \\
\text { médio }\end{array}$ & $\begin{array}{c}\text { Desvio Padrão } \\
\text { (angular) }\end{array}$ \\
\hline Coberturas & 144 & 51 \\
Jurássico/Cretáceo & 139 & 48 \\
Triássico/Jurássico & 135 & 49 \\
Permiano 2 & 137 & 50 \\
Permiano 1 & 22 & 81 \\
\hline
\end{tabular}

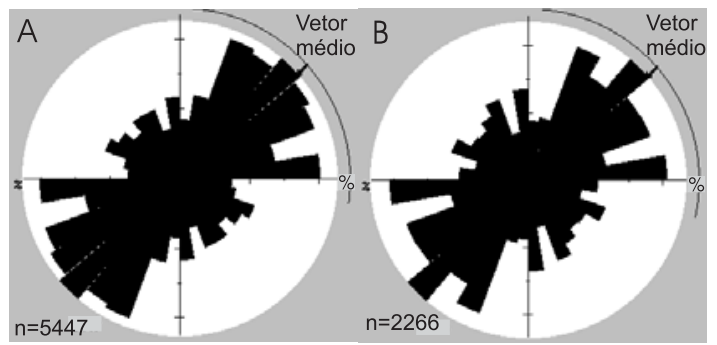

FIGURA 11 - (A) Roseta do conjunto total de feições retilíneas de drenagem na área de estudo; (B) Roseta do conjunto total de feições retilíneas de drenagem da porção sul da área de estudo 


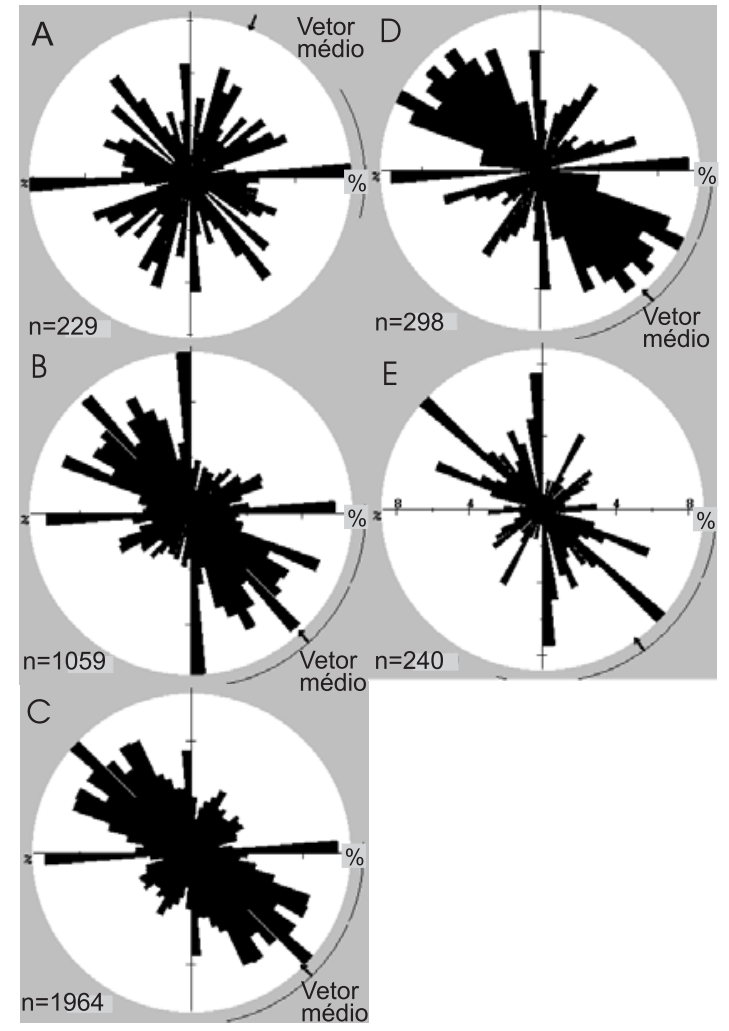

FIGURA 12 - Rosetas de feições retilíneas de drenagem por tipo litoestratigráfico. (A) áreas de afloramento de rochas permianas, Subgrupo Irati e Tatuí - Permiano 1; (B) áreas de afloramento de rochas permianas, Fm. Teresina - Permiano 2; (C) áreas de afloramento de rochas triássicas e jurássicas, Pirambóia/Botucatu; (D) áreas de afloramento de rochas juro-cretáceas, Fm. Serra Geral/Fm. Marília; (E) áreas de afloramento de coberturas sedimentares cenozóicas.

Nos mapas de densidade de zonas de juntas, nota-se que as ocorrências de arenitos asfálticos localizam-se em regiões de valores intermediários a altos (Tabela 1). Isso pode ser observado na porção sul da área de estudo, onde pode-se relacionar a maior densidade à intrusão de rochas básicas e falhamentos, com conseqüente disposição de ocorrências de arenitos asfálticos. Em princípio, as áreas mais fraturadas são mais propícias para a migração secundária de hidrocarbonetos e conseqüente ocorrência de arenitos asfálticos. Entretanto as ocorrências não se localizam diretamente sobre as áreas de alto valor de densidade, o que poderia indicar que as áreas mais fraturadas também são mais dissecadas, aumentando a probabilidade de processos erosionais terem destruído eventuais ocorrências.

O arenito asfáltico encontra-se na borda de altos estruturais provavelmente de idade juro-cretácea. A migração teria ocorrido em direção aos altos estruturais e atingido as rochas reservatório presentes no topo destas estruturas. Estes altos estruturais teriam sido posteriormente erodidos em processo provavelmente iniciado no final do Cretáceo, e as acumulações destruídas. As ocorrências encontradas estão em terrenos remanescentes, preservados da erosão ou parcialmente erodidos. Este padrão é verificado tanto na área Anhembi quanto na Jacu.

Em relação ao padrão de fraturamento conclui-se que as ocorrências de arenitos asfálticos localizam-se nas regiões onde concorrem condições ótimas de migração e acumulação, mas também de preservação em relação à denudação.

\section{AGRADECIMENTOS}

Agradecimentos à FAPESP pelo apoio financeiro, por meio do projeto Auxílio à Pesquisa (Proc. 00/01852-0) e da bolsa de doutorado do primeiro autor (Proc. 99/10417-7). Os autores agradecem aos Professores do INPE Dr. Paulo Veneziani, pelas discussões acerca da intepretação morfoestrutural, e Dr. José Carlos Neves Epiphânio, por ter autorizado a cessão das imagens de satélite. Agradecem ainda aos revisores e editor da Revista do Instituto Geológico, pelas sugestões oferecidas para melhoria do manuscrito.

\section{REFERÊNCIAS BIBLIOGRÁFICAS}

AB’SABER, A.N. 1969. A depressão periférica paulista: um setor das áreas de circundesnudação pós-cretácea na Bacia do Paraná. São Paulo, IGEO-USP, Geomorfologia 11p. (n. 15).

ALMEIDA, F.F.M. 1964. Fundamentos geológicos do relevo paulista: Boletim do Instituto Geográfico e Geológico, 41: 167.

ALIYEV A. 1979. Regional fracturing of the Pamirs and its metallogenic significance. In: Doklady Akad. Nauk, USSR, 250: 90-93. 
ARAÚJO, C.C. 2003. Gênese das ocorrências de arenito asfáltico da borda leste da Bacia do Paraná, SP. Instituto de Geociências, Universidade de São Paulo, São Paulo, Tese de doutoramento, 135p.

ARAÚJO, L.M.; TRIGUIS, J.A.; CERQUEIRA J.R.; FREITAS L.C. DA S. 2000. The atypical Permian Petroleum System of the Paraná Basin, Brazil. In M.R. Mello \& B.J. Katz (eds.) Petroleum systems of South Atlantic margins. AAPG Memoir, 73: 377402.

BATES, R.L. \& JACKSON, J.A. 1987. Glossary of Geology. American Geological Institute, Alexandria, Virginia, 788p.

BEISL, C.H. 1996. Integração de dados de sensoriamento remoto, geologia, gravimetria e topografia para o estudo do arcabouço estrutural em uma parte do compartimento nordeste da bacia do Recôncavo. Instituto Nacional de Pesquisas Espacias, São José dos Campos, Dissertação de Mestrado, 109p.

CREPANI E. 1987. Análise de fraturas através de imagens fotográficas de baixa resolução espacial: uma contribuição ao estudo da evolução tectônica da região da Chapada do Araripe - NE do Brasil. Instituto de Geociências, Universidade de São Paulo, São Paulo, Tese de Doutoramento 139p.

DAEE-UNESP. 1984. Landim, P.M.B. (coordenador), Mapa Geológico do Estado de São Paulo, escala 1:250.000 - Folha Botucatu.

FRANZINELLI, E. 1972. Arenitos asfálticos do estado de São Paulo. Instituto de Geociências, Universidade de São Paulo, São Paulo, Tese de Doutoramento, 104p.

GONTIJO, A. H. F. 1999. Morfotectônica do médio vale do rio Paraíba do Sul: região da Serra da Bocaina, Estados de São Paulo e Rio de Janeiro. Tese de Doutoramento, 259p.

HACHIRO, J.; COIMBRA, A.M.; MATOS, S.L.F. 1993. O caráter cronoestratigráfico da Unidade Irati. In: IGCE-UNESP, Simpósio sobre cronoestratigrafia da Bacia do Paraná, 1, Rio Claro, Rio Claro, Resumos, 62-63.
KING, L.C. 1956. A geomorfologia do Brasil oriental: Revista Brasileira de Geografia, (18)2: 147.

MATOS, S.L.F. 1995. O contato entre o Grupo Passa Dois e a Formação Pirambóia na borda leste da Bacia do Paraná no Estado de São Paulo. Instituto de Geociências, Universidade de São Paulo, São Paulo, Dissertação de Mestrado, 110 p.

MATOS, S.L.F. \& COIMBRA, A.M. 1997. Sucessão de fácies na Camada Porangaba, Grupo Passa Dois, Estado de São Paulo. In: SBG, Revista Brasileira de Geociências, 27:377-366.

MATTOS, J.T.; BALIEIRO, M.G.; SOARES, P.C.; BARCELLOS, P.E.; MENESES, P.R.; CSORDAS, S.M. 1982. Análise morfoestrutural com uso de imagens MSS/ Landsat e Radar para pesquisa de hidrocarbonetos no Estado de São Paulo. Relatório INPE-2445-RTR/015. São José dos Campos, 170p.

NICKELSEN, R.P. 1974. Early jointing and cumulative fracture patterns. In: Utah Geological Association Publication, International Conference on the New Basement Tectonic, 1, Proceedings, 5:193-199.

PLICKA 1974. Observations on Joint Zones in Moravia, Czechoslovakia. In: New basement tectonics contribution, 30:279-289.

RAMSAY, J.G. \& HUBER, M.I. 1987. The techniques of modern structural geology: folds and fractures. London, Academic Press, v. 2, 700 p.

ROSS, J.L.S. \& MOROZ, I.C. 1997. Mapa geomorfológico do Estado de São Paulo. Laboratório de Geomorfologia, Depto. de Geografia, FFLCH, USP/ Laboratório de Cartografia Geotécnica, Geologia Aplicada, IPT/ Fapesp, Fundação de Amparo à Pesquisa do Estado de São Paulo, Relatório 64 p. (escala 1:500.000).

SOARES, P.C. 1974. Elementos estruturais da parte nordeste da Bacia do Paraná: Classificação e Gênese. In: SBG, Congresso Brasileiro Geologia, 28, Porto Alegre, Anais, 4:107-121. 
SOARES, P.C. \& FIORI, P. 1976. Lógica e sistemática na análise e interpretação de fotografias aéreas em geologia. In: Noticia Geomorfológica, 16(32):71-40.
VENEZIANI, P. 1987. Análise de movimentos da tectônica rúptil e rúptil-dúctil através da interpretação de produtos de sensores remotos na região do Espinhaço meridional (MG): uma correlação com processos evolutivos. Instituto de Geociências, Universidade de São Paulo, São Paulo, Tese de Doutoramento, 186 p.

Endereço dos autores:

Carlos César de Araújo - Rua Galileo Emendabili, 109, Jardim Atlântico, São Bernardo do Campo, SP, CEP 09780-287.E-mail: ccaraujo@usp.br

Jorge Kazuo Yamamoto - Instituto de Geociências, Universidade de São Paulo, Rua do Lago, 562, Cidade Universitária, São Paulo, CEP 05508-900. E-mail: jkyamamo@usp.br

Vanessa Madrucci - Instituto de Geociências, Universidade de São Paulo, Rua do Lago, 562, Cidade Universitária, São Paulo, CEP 05508-900. E-mail: madrucci@usp.br 